\title{
R. Wójcik
}

Lodz University of Technology, Institute of Machine Tools and Production Engineering, Stefanowskiego 1/15, 90-924 Łódź

rwojcik@p.lodz.pl

\section{EFFECT OF CARBON CONTENT IN STAINLESS STEELS ON QUANTITY OF GRINDING ENERGY}

\begin{abstract}
The paper presents a study of the process of grinding stainless steels with different carbon contents. Verified the size and scope of the energy which is introduced in the surface layers for different types of abrasive grains and binders. The influence of parameters in plunge grinding process was considered in studies. The energy ratio was used for this purpose, which was calculated by multiplying energy and time of grinding wheel contact with the workpiece. To investigate influence of different carbon content on the level of energy density generated during grinding process special parameter $\mathrm{B}_{\mathrm{p}}$ have been evaluated. The grinding tests were conducted in dry grinding technique.
\end{abstract}

Key words: grinding, stainless steel

\section{INTRODUCTION}

Stainless steel products are manufactured in countless variations and requirements. They are applicable in wide areas and domains of life. Regardless of the version and destination, these devices have a common property, are made from expensive materials, which include the different varieties of stainless steel. In fact, these are mainly steels with specified participation of chromium and nickel, their rustproof provides the chromium content of $12 \%$, growth of this component increases its resistance to state aggressiveness in particular chemical environments. The chromium content determines the structure. Today there are many types of steel, from ferritic steels $(17 \% \mathrm{Cr}$ ) to martensitic steels (up to $20 \% \mathrm{Cr}$ ). Figure 1 shows the classification of stainless steels depending on the share of individual elements, not taken into account the consideration of precipitation hardened steels

Each of the groups presented in Figure 1 includes appropriate combinations of alloying components deciding on their use and purpose in certain areas, depending on the technological requirements.

An important component determining rustproof is also carbon which tends to form carbides. Two types of stainless steel with extreme carbon content were selected for testing. From the first group of the used steel $\mathrm{X} 42 \mathrm{Cr} 13$, possible for the heat treatment, the carbon content is on the level of $0,42 \%$. The other stainless steel is $1 \mathrm{H} 18 \mathrm{~N} 9 \mathrm{~T}$ with carbon content of $0.10 \%$ (chemical composition was analyzed with the quantometer ARL-360). 




Fig. 1. Stainless steels classification depending on the chemical composition

Using the processes of quenching and tempering in the first case (X42Cr13) may be obtained the relevant properties of the surface layer, which increases the resistance to fatigue failures.

The decrease in carbon content creates a structure resistant to chemically aggressive environments. Plunge grinding process was performed on flat samples in one pass. In real terms grinding without cutting fluid should be avoided. However, the aim was to determine the maximum value of energy flux during the grinding process of steel. Liquid cooling lubricating share reduce the fraction of energy flux, what does not mean that the problem of damage of surface layer does not exist.

Efforts to conduct research for a broad group of abrasives, included new materials solutions of grinding wheels that have arisen as a result of research over time. Selected abrasives and their parameters are shown in Table 1.

Table 1. Characteristics of grinding wheels

\begin{tabular}{|c|c|c|c|}
\hline Abrasive & $\begin{array}{c}\text { Grain and } \\
\text { hardness }\end{array}$ & Binder & Designation in the development \\
\hline $38 \mathrm{~A}$ & $60 \mathrm{~J}$ & VBE & $38 \mathrm{~A} / \mathrm{J}$ \\
\hline $25 \mathrm{~A}$ & $80 \mathrm{G}$ & VBEP & $25 \mathrm{~A} / \mathrm{G}$ \\
\hline $3 \mathrm{XGP}$ & $54 \mathrm{~K}$ & VX & $3 \mathrm{XG} / \mathrm{K}$ \\
\hline $3 \mathrm{TGP}$ & $54 \mathrm{~K}$ & $\mathrm{VY}$ & $3 \mathrm{TG} / \mathrm{K}$ \\
\hline 1TGP & $46 \mathrm{G}$ & VX & $1 \mathrm{TG} / \mathrm{G}$ \\
\hline $3 \mathrm{SG}$ & $60 \mathrm{~K}$ & $\mathrm{VS}$ & $3 \mathrm{SG} / \mathrm{K}$ \\
\hline
\end{tabular}

As is well known that temperature generated during grinding process has great influence on material properties of final product. The temperature is directly connected with power density, which can be easily evaluated by means of dynamometers or power measuring equipment [13]. To have opportunity to compare results concerning power generation for different types of stainless steels, parameter $\mathrm{B}_{\mathrm{p}}$ has been used. The $\mathrm{B}_{\mathrm{p}}$ parameter is a product of the power density $\mathrm{P}^{\prime}$ and grinding wheel/workpiece contact time $t_{c}(1)$.

$$
B_{p}=P^{\prime} \cdot t_{c}
$$


For obtaining power density $\mathrm{P}^{\prime}(2)$ tangential component force $\mathrm{F}_{t}$ have been measured during the grinding tests. Others parameters such as grinding wheel speed, grinding width can be easily calculated.

$$
P^{\prime}=\frac{F_{t} v_{s}}{b_{D} \cdot l_{e}}
$$

Time of contact between grinding wheel and work material can be calculated from formula (3).

$$
t_{c}=\frac{l_{e}}{v_{w}}
$$

After putting into formula (1) formulas (2) and (3) equation for indicator $\mathrm{B}_{\mathrm{p}}$ is as follows.

$$
B_{p}=\frac{F_{t} v_{s}}{b_{D} \cdot l_{e}} \cdot \frac{l_{e}}{v_{w}}
$$

Finally indicator $\mathrm{B}_{\mathrm{p}}$ for grinding flat surface is represented as formula (5)

$$
B_{p}=\frac{F_{t} \cdot v_{s}}{b_{D} \cdot v_{w}} \quad\left[\frac{W \cdot s}{m m^{2}}\right]
$$

where:

$F_{t^{-}}$tangential force component $[\mathrm{N}]$,

$v_{\mathrm{s}^{-}}$grinding wheel speed $[\mathrm{m} / \mathrm{s}]$,

$b_{D^{-}}$grinding width $[\mathrm{mm}]$,

$v_{\mathrm{w}}$ - workpiece speed $[\mathrm{m} / \mathrm{s}]$,

$l_{e}$-geometric length of the grinding wheel contact with the material.

\section{GRINDING PROCESS PARAMETERS}

The testing samples were flat, made in two dimensions $100 \times 40 \times 10 \mathrm{~mm}$ and $100 \times 40 \times 4 \mathrm{~mm}$. Samples thickness $(40 \mathrm{~mm})$ assured resistance to thermal deformation (second variant was used to further study on the distribution of internal stresses). Chemical composition of examined stainless steels are given in Table 2.

Table.2. Chemical composition of examined stainless steels, wt.\%

\begin{tabular}{|c|c|c|c|c|c|c|c|c|}
\hline Designation & $\mathrm{C}$ & $\mathrm{Si}$ & $\mathrm{Mn}$ & $\mathrm{P}$ & $\mathrm{S}$ & $\mathrm{Cr}$ & $\mathrm{Ni}$ & $\mathrm{Ti}$ \\
\hline X42Cr13 & $0.38-0.45$ & $03-0.5$ & $0.2-0.4$ & 0,03 & 0.03 & $12-14$ & 8.0 & -- \\
\hline 1H18N9T & max.0.10 & 0.8 & 2.0 & 0.04 & 0.03 & $17-19$ & $8.0-10$ & 0.8 \\
\hline
\end{tabular}

Tests performed on flat samples due to material costs, using plunge grinding in one pass on the grinder SPD-30 with the parameters range shown in Fig. 2, which only shows grinding wheels designations and process parameters.

For measuring the grinding force components the dynamometer 9272 was used, where samples holder was installed. The signal from dynamometer was sent to the amplifier 5011A and the card DAS 1602, which was placed in the PC. The station, together with the software was described in articles $[11,12]$. 
Designations

$38 A / J$
$25 A / G$
$3 S G / K$
$3 X / K$
$3 T G / K$
$1 T G / G$

Process parameters

Dry

machining

(S)

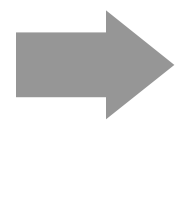

Fig. 2. Summary of designations and parameters of the grinding process

\section{RESULTS}

Research evaluation allowed to determine the effect of process parameters on grinding indicator $\mathrm{B}_{\mathrm{p}}$ giving the response about state of the energy of grinding process (energy flux density). Only selected results are presented due to the broad spectrum of research.

As a result of high energy generated during grinding process structural changes may appear. This phenomena might cause dimensional differences in accordance to parameters which have been set on the grinder machine. The actual depth of cut was checked on the profilometer. Measurement of spatial 3D topography implemented using profilograph Hommel TurboWaveline60.

Device allows to visualize roughness and waviness of the surface layer in the form of topography maps. The measurement was carried out in following way: entire sample surface was levelled then the grinding wheel was shifted in order to create a datum in respect of which the actual depth of cut was referred (Fig. 3, for example).

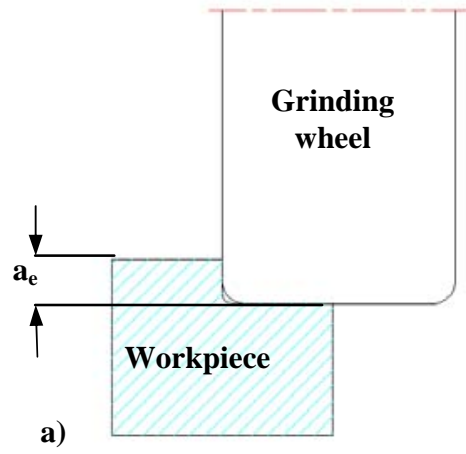

Fig. 3. Method of checking actual depth of grinding: a) scheme, b) result

Figure 4 shows the distribution of points from different range of the parameter $\mathrm{v}_{\mathrm{w}}$, chosen equations describe the distribution of the results of research. Tests for individual points were repeated three times.

The increase in work piece speed and depth of cut determines energy state. The highest values of energy generated during grinding process have been observed for $\mathrm{v}_{\mathrm{w}}=0.1 \mathrm{~m} / \mathrm{s}$. At that time the most of energy is generated and the greatest damages of surface layer have been observed. This results in material tempering, structural changes and many other negative consequences in case of $0.05 \mathrm{~mm}$ allowance. All surface layer damages are catastrophic for further operating. 


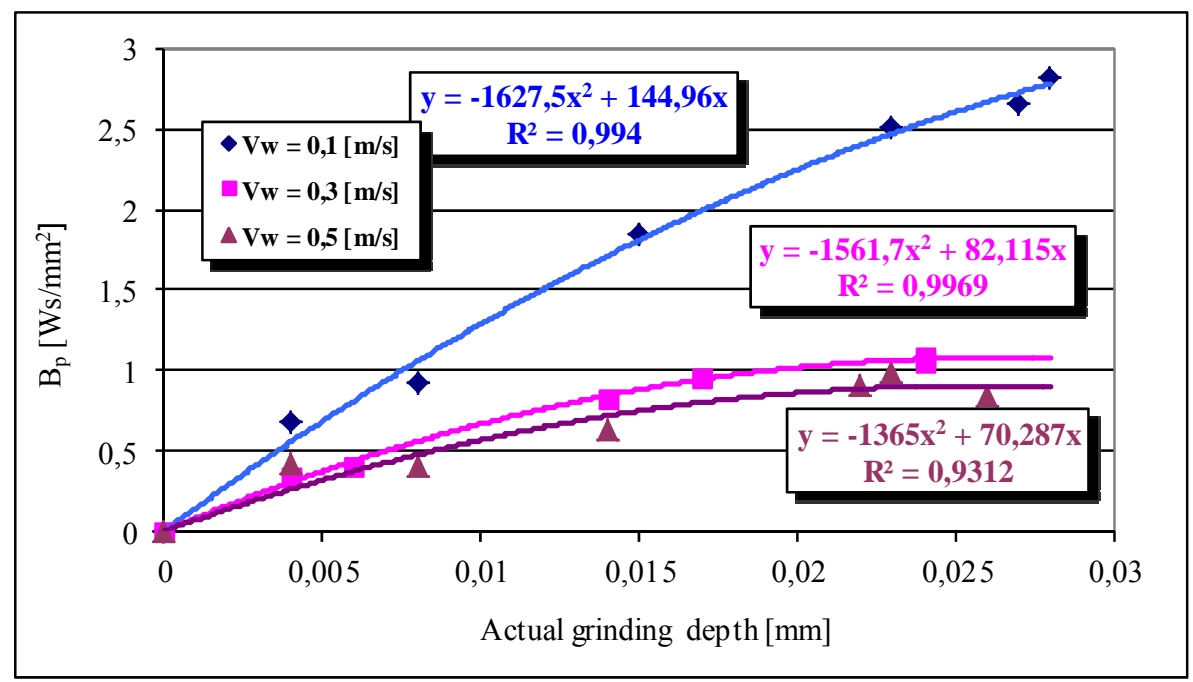

Fig. 4. Influence of grinding process parameters $a_{r}, v_{w}$ on the value of indicator $B_{p}$

Also presented a graph showing the influence of the parameters, the grinding subject speed and adjustable allowance. Both values in a large extent decide on indicator value $\mathrm{B}_{\mathrm{p}}$ - the energy state of the process. This is important for the state of the surface layer in the case of the heat-treated materials as well as the materials with a low carbon content that are not subject to heat treatment. This concerns burns that cover the entire range from streak to continuous burns, also obtained secondary recrystallization and other forms of the surface changes.

In case of stainless steel with a low carbon content, any surface layer damage determine susceptibility to intergranular corrosion in particular for the grinding process which is technologically final operation.

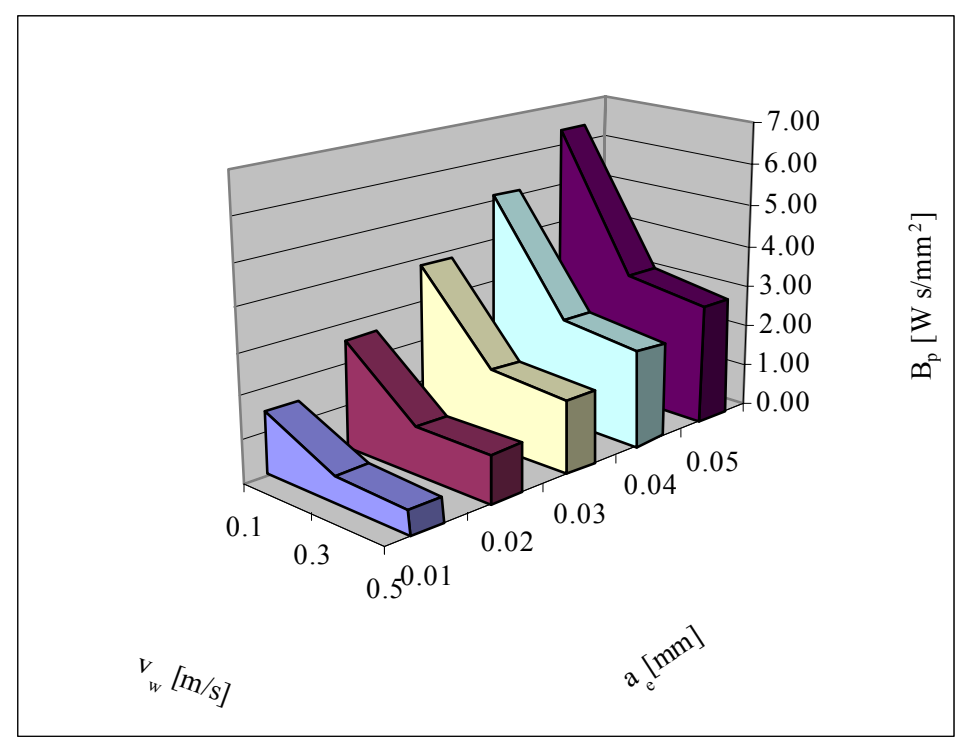

Fig. 5. Influence of grinding process parameters $a_{r}, v_{w}$ on the value of indicator $B_{p}$

Later in this article in Figure 6 presented the shares of energy flux density generated by the particular grinding wheels during tests of steel X42Cr13, heat treated to a hardness of 56 HRC. In all examined cases involving individual grinding wheels with the same grinding process parameters, tests were performed without the participation of fluids, such steps have 
been taken deliberately to determine the flux density level. Under normal conditions of grinding process cooling fluids are used to reduce heat load in surface layer.

Presented speed ranges of the object $\mathrm{v}_{\mathrm{w}}$ minimum $0.1 \mathrm{~m} / \mathrm{s}$ and maximum $0.5 \mathrm{~m} / \mathrm{s}$. In terms of energy studied areas can be divided into two zones. The first range $5.39-4.8 \mathrm{~W} \mathrm{~s} / \mathrm{mm}^{2}$ concerns maximum allowance $a_{\mathrm{e}}=0.05 \mathrm{~mm}$ and $\mathrm{v}_{\mathrm{w}}=0.1 \mathrm{~m} / \mathrm{s}$. Then, the contact time with surface layer is much longer, which results in greater thermal load in surface.

These are conventional grinding wheels made $25 \mathrm{~A} / \mathrm{G}$ of precious aloxite $\mathrm{Al}_{2} \mathrm{O}_{3}, 38 \mathrm{~A} / \mathrm{J}$ and chromium aloxite $25 \mathrm{~A} / \mathrm{G}$. The highest energy flux obtained for the microcorundum grinding wheel $\mathrm{SG} / \mathrm{K}$. In the second area were grinding wheels from XG and TG groups, they are characterized by a specific grain structure in the form of rods with ratio of 1:8 in diameter to length. Table 3 summarizes the results obtained during tests, specified surface layer damages.

Table 3. Summary of the energy flux grinding process

\begin{tabular}{|c|c|c|c|c|c|}
\hline \multicolumn{2}{|c|}{ Grinding wheel } & Steel & $\begin{array}{c}\mathrm{B}_{\mathrm{p}} \\
{\left[\mathrm{W} \mathrm{s} / \mathrm{mm}^{2}\right]}\end{array}$ & Steel & $\begin{array}{c}\mathrm{B}_{\mathrm{p}} \\
{\left[\mathrm{W} \mathrm{s} / \mathrm{mm}^{2}\right]}\end{array}$ \\
\hline Area „I” & $3 \mathrm{SG} / \mathrm{K}$ & \multirow{6}{*}{$\mathrm{X} 42 \mathrm{Cr} 13$} & 4.98 & \multirow{6}{*}{ 1H18N9T } & 11.3 \\
\hline & $25 \mathrm{~A} / \mathrm{G}$ & & 4.12 & & 7.65 \\
\hline & $38 \mathrm{~A} / \mathrm{J}$ & & 3.84 & & 8.23 \\
\hline \multirow[t]{3}{*}{ Area „II” } & $3 \mathrm{XG} / \mathrm{K}$ & & 2.86 & & 4.12 \\
\hline & $3 \mathrm{TG} / \mathrm{K}$ & & 2.21 & & 3.75 \\
\hline & $1 \mathrm{TG} / \mathrm{G}$ & & 1.32 & & 2.04 \\
\hline
\end{tabular}

In Figures 6 to 7 results concerning application of different types of grinding wheels obtained for two types of stainless steels are presented. In all cases, the grinding wheels from XGP and TGP groups depending on the tools hardness obtained three times less impact energy compared to conventional grinding wheels. The smallest value of energy flux obtained during the grinding process using $1 \mathrm{TG} / \mathrm{G}$ grinding wheel, here in both cases studied steels with the same process parameters, the ratio $B_{p}$ was about six times lower, in none of these cases did not observe any damage to the surface layer. The only problem occurred called "pouring out the wheel", which accelerate self-sharpening.

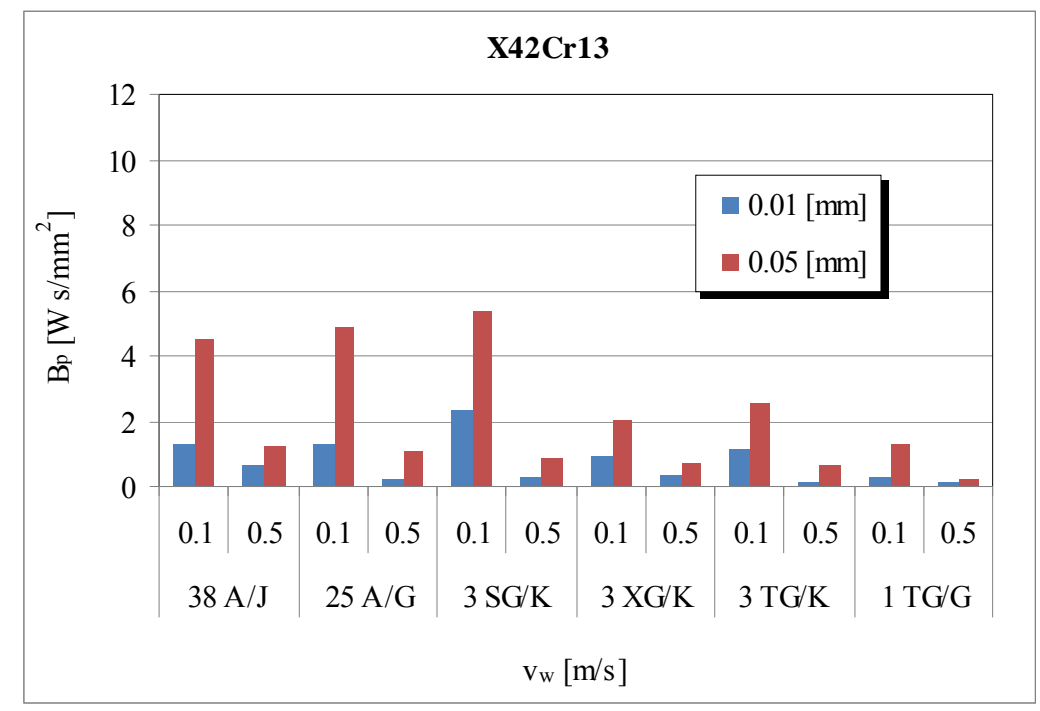

Fig. 6. Energy state level in the process of dry grinding of steel $\mathrm{X} 42 \mathrm{Cr} 13$ 
Completed studies show that the structure of the grain within the meaning of shape is crucial for energy flux in plunge grinding. New generations of grains interact much more advantageous for the final condition of surface layer, this applies to both stainless steel with a high degree of carbon saturation and when the carbon saturation is several times smaller. In the latter case it is crucial for the formation of intergranular corrosion.

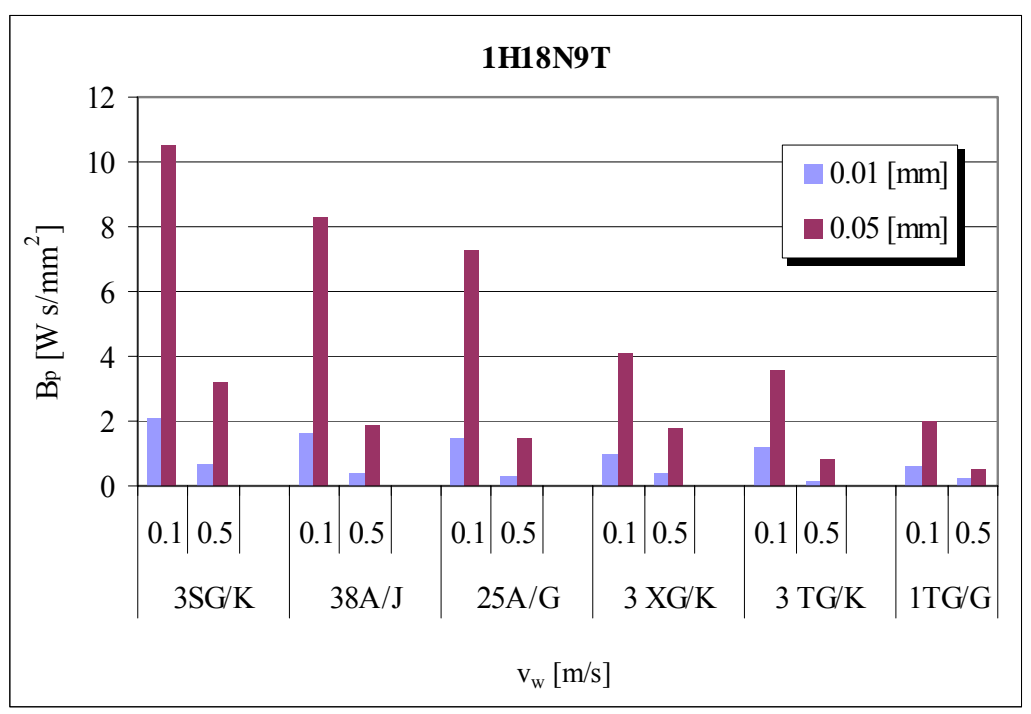

Fig. 7. Energy state level in the process of dry grinding of steel $1 \mathrm{H} 18 \mathrm{~N} 9 \mathrm{~T}$

\section{CONCLUSIONS}

Research of specific stainless steels indicate that in case of increase of the carbon content the energy effect of plunge grinding process takes place at a lower level. Temper causes the surface layer requires less energy flux compared to steels with lower carbon content which nevertheless results in tempering, changes in microhardness and grinding burn.

However, if the grinding process of steel with carbon content at level of $0.10 \%$ at temperatures above $500^{\circ} \mathrm{C}$ occurs release of carbon excess in the form of network system on the austenite grain boundaries. This phenomenon affects the formation of intergranular corrosion. This is due to the fact that the diffusion rate of carbon is greater than the diffusion rate of chromium

Carbon is required for the precipitation of carbide is trapped at the grain area, while chromium only from areas that adhere to the grain boundaries. Accordingly, near the grain austenite matrix becomes depleted in chromium. As a result of this process, border areas are becoming not resistant to corrosion. Inclinations of steel to intergranular corrosion is dependent on the carbon concentration in the matrix, the temperature and time of sensitization.

During the grinding process of steel $1 \mathrm{H} 18 \mathrm{~N} 9 \mathrm{~T}(0.10 \% \mathrm{C})$ noticed differences in the density distribution of energy resulting from the percentage of carbon. However, not for all tested grinding wheels this is clear. Energy ranges for each wheel and materials vary. For the same grinding wheels and grinding parameters process was at much higher energy ranges than with higher percentage of carbon. In the case of stainless steel grinding parameters $\mathrm{v}_{\mathrm{s}}=25 \mathrm{~m} / \mathrm{s}$, 
$\mathrm{V}_{\mathrm{W}}=0.1 \mathrm{~m} / \mathrm{s}$, and $\mathrm{a}_{\mathrm{e}}=0.05 \mathrm{~mm}$ was obtained damage in surface layer at depth of $0.08 \mathrm{~mm}$, this is four times less than the depth of the structural alloy steel or tool steel.

\section{REFERENCES}

1. Dudek A., Wrońska A: Corrosion of steel type SNOK and ways to prevent it [in Polish], Stal. Metale \& Nowe Technologie. Vol. 1-2 (2014), 88-91.

2. Cobb H. M.: The History of Stainless Steel, ASM International, 2010.

3. Nowacki J.: Duplex steel and its weldability [in Polish]. Przegląd Spawalnictwa, 10 (2008), 3444.

4. Baszkiewicz J., Kamiński M.: Basics of corrosion of materials [in Polish]. Oficyna wydawnicza Politechniki Warszawskiej, Warszawa 2007.

5. Krakowiak S.: Pitting corrosion of alloy steels. Corrosion processes [in Polish]. Gdańsk 2007.

6. Korzeniewski H.: Background to the study effect of temperature on the corrosion resistance grinding stainless steel pipe water purification [in Polish]. XXVII Naukowa Szkoła Obróbki Ściernej, Koszalin 2004.

7. Partington E.: Application of corrosion-resistant steel in the food industry, Euroinox, 7, 2002

8. Metalworking World.: Magazine Business and Technology Corporation, Sandvik Coromant.

9. Burakowski T., Wierzchoń T.: Surface engineering of metals [in Polish]. WNT Warszawa 1995.

10. Marciniak J.: Biomaterials for bone surgery [in Polish]. Wydawnictwo Politechniki Ślaskiej 1992.

11. Wójcik R.: New media and ways to bring the grinding zone [in Polish]. Archiwum Technologii Maszyn i Automatyzacji, 28, 4 (2008), 137-145.

12. http//www.atlassteels.co.nz.: The Atlas Steel Technical Handbook of Stainless, Atlas Steel Technical Department, 2010.

13. Kruszyński B., Wójcik R.: Residual Stress in Grinding, Journal of Materials Processing Technology 109 (2001), 254-257.

14. www.hazmetal.com/f/kutu/1236776229. 